Vol.1 No.1 Januari 2018

ISSN 2614-2775

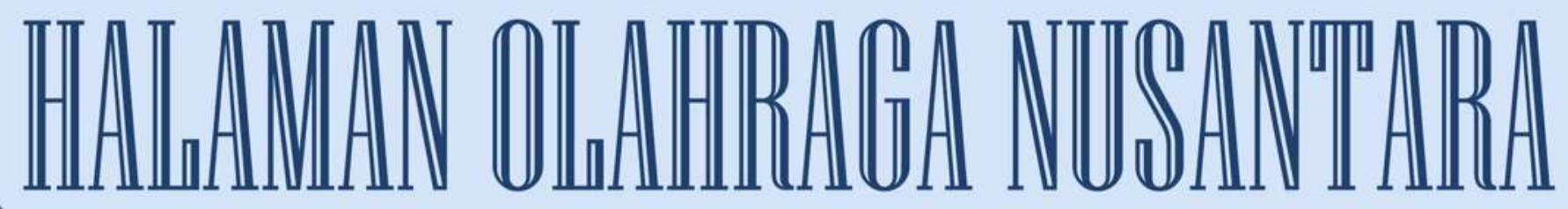

Curnal \&lmu Q Xeolahragaan

Diterbitkan Oleh:

Program Studi Pendidikan Olahraga

Pakultas Keguruan dan Ilmu Pendidikan

Universitas PGRI Palembang

\begin{tabular}{|c|c|c|c|c|c|}
\hline Jurnal & Volume & Nomor & Halaman & Palembang & ISSN \\
\hline IItaman Oahraya Vissantara & 1 & 1 & $1 \cdot 132$ & 2018 & 2014.27175 \\
\hline
\end{tabular}


Artikel Ilmiah

Perbedaan Variasi Latihan Juggling dan Rasio Koordinasi Mata-Kaki terhadap Hasil Kontrol Bola dari Tendangan Jarak Jauh Sepak Bola Hengki Kumbara

Hubungan Antara Kekuatan Otot Tungkai dan Kekuatan Otot Lengan terhadap Hasil Kecepatan Renang 50 Meter Gaya Bebas pada Atlet Putri Club Bangka Swimming

Farizal Imansyah

Motivasi Mahasiswa PGSD dalam Olahraga Rekreasi di Water Fun Kota Palembang

M. TaheriAkikbar

Pengaruh Metode Sirkuit terhadap Kemampuan Teknik Dasar Sepakbola pada Kegiatan Ekstrakurikuler Siswa SMAN 5 Kabupaten Tebo Alek Oktadinata

Kontribusi. Daya Ledak Otot Thung:kai dan Kelentukan dengan [1asil] Lompat Tinggi Gaya Flop Mahasiswa Program Studi Pendidikan Olahraga Universitas PG:RIPalembang IIham Arvan Junaidi

Kemampuan Meng.gining Bola (IStudi Korelasional Kecepatan ( $\left.x_{1}\right)$ dan Kelineahan $\left(x_{2}\right)$ dengan Kemampuan Dribel pada Permainan Sepabola Siswa Sekolah Menengah Pertama) Putwi Cicilla Kristina

Revitalisasi Masyarakat ¿iban/Perkotaan Melalui Olahraga Petanque Arcdo okilanda

Peranan Mata Pelajaran Pendidikan Jasmani dalam Meningkatkan Kesadaran Kesehatan \$iswa đi Lingkungan \$ekolah Dasar

Negeri nur Tegalkalong Kabupaten sumedang

№ Siti nurfaeni Sofa dan Anggi Setia Lengkana

Peran Motor Educability di dalam Meningkatan Keterampilan Olahraga pada Pembelajaran Penjas

gieru Syarili Lesmana

MơtivasiAnggota Pusat Kebugaran dalam Mengikuti Latihan Fitness padaKota Sekaycu Sugar Wanto

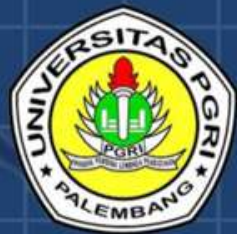

Program Studi Pendidikan Olahraga Fakultas Keguruan dan Ilmu Pendidikan Universitas PGRI Palembang 
ISSN 2614-2775

\section{HALAMAN OLAHRAGA NUSANTARA}

Jurnal Ilmu Keolahragaan

Volume 1, Nomor 1, Januari 2018

Pelindung/Penasehat

Dr. H. Bukman Lian, M. M., M. Si.

Penanggung Jawab

Dr. Dessy Wardiah, M. Pd.

Ketua Dewan Redaksi

Drs. M. Nirwan, M. Pd.

\section{Wakil Ketua Dewan Redaksi}

Ilham Arvan Junaidi, M. Pd.

\section{Sekretaris}

Nasrullah, M. Pd.

Penyunting Pelaksana

Rafel Orlando, M. Pd

Ardo Okilanda, M. Pd

\section{Penyunting Ahli/ Mitra Bestari}

Prof. Dr. A. Sofyan Hanif, M. Pd (Universitas Negeri Jakarta)

Dr. Ronni Yenes, M. Pd (Universitas Negeri Padang)

Dr. Putri Cicilia Kristina, M. Pd (Universitas PGRI Palembang)

\section{Tata Usaha}

M. Taheri Akbar, M. Pd

\section{Setting:}

Dede Dwiansyah Putra, M. Pd

Alamat Redaksi:

Prodi Pendidkan Olahraga Fakultas Keguruan Ilmu dan Pendidikan Universitas PGRI Palembang

Jl. Jendral A. Yani Lorong Gotong Royong 9/10 Ulu Palembang Telp. 0711-510043, Fax. 0711-514782

e-mail jurnal: rafelorlando333@gmail.com

e-mail : ardo.oku@ univpgri-palembang.ac.id

website: univpgri-palembang.ac.id 


\section{DAFTAR ISI}

Perbedaan Variasi Latihan Juggling dan Rasio Koordinasi Mata-Kaki terhadap Hasil Kontrol Bola dari Tendangan Jarak Jauh Sepak Bola

Hubungan Antara Kekuatan Otot Tungkai dan Kekuatan Otot Lengan terhadap Hasil Kecepatan Renang 50 Meter Gaya Bebas pada Atlet Putri Club Bangka Swimming

- Farizal Imansyah

Motivasi Mahasiswa PGSD dalam Olahraga Rekreasi di Water Fun Kota Palembang

- $\quad$ M. Taheri Akhbar

Pengaruh Metode Sirkuit terhadap Kemampuan Teknik Dasar Sepakbola pada Kegiatan Ekstrakurikuler Siswa SMAN 5 Kabupaten Tebo

- Alek Oktadinata

Kontribusi Daya Ledak Otot Tungkai dan Kelentukan dengan Hasil Lompat Tinggi Gaya Flop Mahasiswa Program Studi Pendidikan Olahraga Universitas PGRI Palembang

- Ilham Arvan Junaidi

Kemampuan Menggiring Bola (Studi Korelasional Kecepatan $\left(\mathrm{x}_{1}\right)$ dan Kelincahan $\left(\mathrm{x}_{2}\right)$ dengan Kemampuan Dribel pada Permainan Sepabola Siswa Sekolah Menengah Pertama)

- Putri Cicilia Kristina

Revitalisasi Masyarakat Urban/Perkotaan Melalui Olahraga Petanque

- $\quad$ Ardo okilanda

Peranan Mata Pelajaran Pendidikan Jasmani dalam Meningkatkan

Kesadaran Kesehatan Siswa di Lingkungan Sekolah Dasar

Negeri III Tegalkalong Kabupaten Sumedang

- $\quad$ N. Siti nur'aeni Sofa dan Anggi Setia Lengkana

Peran Motor Educability di dalam Meningkatan Keterampilan

Olahraga pada Pembelajaran Penjas

- Heru Syarli Lesmana 
Motivasi Anggota Pusat Kebugaran dalam Mengikuti Latihan Fitness pada Kota Sekayu

Sugar Wanto 


\title{
HUBUNGAN ANTARA KEKUATAN OTOT TUNGKAI DAN KEKUATAN OTOT LENGAN TERHADAP HASIL KECEPATAN RENANG 50 METER GAYA BEBAS PADA ATLET PUTRI CLUB BANGKA SWIMMING
}

\author{
Oleh: Farizal Imansyah \\ (Dosen Universitas PGRI Palembang)
}

\begin{abstract}
Abstrak
Tujuan dalam penelitian ini adalah untuk mengetahui adakah hubungan antara kekutan otot tungkai dan kekuatan otot lengan terhadap hasil kecepatan renang 50 meter gaya bebas pada atlet putri Club Bangka Swimming. Tujuan penelitian ini adalah untuk mengetahui ada atau tidaknya hubungan antara kekuatan otot tungkai dan kekuatan otot lengan terhadap hasil kecepatan renang 50 meter gaya bebas pada atlet putri Club Bangka Swimming. Metode penelitian yang di gunakan, yaitu metode korelasi. Sampel penelitian ini yaitu atlet putri yang mengikuti latihan di club Bangka Swimming sebanyak 10 orang atlet. Teknik analisis data menggunakan rumus korelasi product moment, yang gunanya untuk menguji kebenaran hipotesis terima atau di tolak bergantung dari hasil data yang di peroleh. Hasil penelitian menunjukkan bahwa $F_{\text {hitung }}>F_{\text {tabel }}$ atau 4,51 > 4,26, maka tolak Ho dan terima Ha artinya terdapat hubungan yang signifikan antara kekuatan otot tungkai dan kekuatan otot lengan terhadap hasil kecepatan renang 50 meter gaya bebas pada atlet putri club Bangka swimming. Maka dapat di simpulkan bahwa ada hubungan antara kekuatan otot tungkai dan kekuatan otot lengan terhadap hasil kecepatan renang 50 meter gaya bebas pada atlet putri club Bangka Swimming. dan Peneliti memberikan saran kepada guru, pelatih olahraga renang agar atlet perlu memperhatikan kekuatan otot tungkai dan kekuatan otot lengan untuk menunjang kecepatan perenang dalam berenang sesuai gaya yang sedang diajarkan atau dilatih.
\end{abstract}

Kata Kunci: Kekuatan Otot Tungkai, Lengan, Kecepatan Renang

\section{CORRELATION BETWEEN THE POWER OF LEG MUSCLE AND ARM MUSCLE TOWARD THE 50 METER SPEED RESULTS FREE STYLE SWIMM AT BANGKA SWIMMING CLUB ATLET}

\begin{abstract}
The purpose of this research is to know is there is correlation between leg muscle strength and arm muscle strength to result of 50 meter freestyle swim at Club Bangka Swimming athlete. The purpose of this study was to determine whether or not there is a correlation between leg muscle strength and arm muscle strength to the result of 50 meters freestyle swim at Club Bangka Swimming athlete. Research method that is used, that is correlation method. Samples of this study are female athletes who follow the exercises at the club Bangka Swimming as many as 10 people
\end{abstract}


athletes. Data analysis techniques using product moment correlation formula, which is useful to test the truth of the hypothesis received or rejected depending on the results of data obtained. The results showed that Fcount> Ftable or 4.51>4.26, then reject $\mathrm{Ho}$ and thank $\mathrm{Ha}$ means there is a significant correlation between leg muscle strength and arm muscle strength to the result of 50 meters freestyle swim speed at the club club athlete athlete Bangka swimming. Then it can be concluded that there is a correlation between leg muscle strength and arm muscle strength to the result of 50 meters freestyle swim at the athlete of woman Bangka Swimming club. and the researcher advises the teacher, the swimming sports coach to get an athlete to pay attention to the strength of the leg muscles and arm muscle strength to support the swimmer's speed in swimming according to the style being taught or trained.

Keywords: Limb Muscle Strength, Arm, Swimming Speed

\section{A. PENDAHULUAN}

Bill Sweetenham dan John Atkinson (2003) mendifinisikan renang sebagai salah satu jenis olahraga yang membutuhkan dua perencanaan latihan, perencanaan jangka panjang dan perencanaan jangka pendek untuk membantu setiap olahragawan agar dapat berprestasi secara maksimal mungkin.

Agung Purwandono Saleh (2008 : 20), mengartikan renang sebagai salah satu jenis olahraga yang digemari oleh berbagai lapisan masyarakat karena dapat dilakukan oleh anak-anak dan orang dewasa baik itu laki-laki maupun perempuan. Olahraga renang mempunyai tujuan yang bermacam-macam diantaranya untuk olahraga pendidikan, olahraga rekreasi, rehabilitasi, dan olahraga prestasi.

Renang yang biasa dilakukan oleh para perenang, yang juga selalu muncul dalam setiap lomba terdiri atas empat gaya, yaitu (1) gaya bebas atau crawl stroke, (2) gaya dada atau breast stroke, (3) gaya kupu-kupu atau butterfly stroke, dan (4) gaya punggung atau back stroke. Keempat gaya tersebut masingmasing mempunyai tingkat kesulitan sendiri-sendiri (Thomas, 2000: 10)

Renang gaya bebas ( $\mathrm{crawl}$ ) pertama kali mulai diperkenalkan oleh Hnery Wickham, seorang perenang dari Australia pada akhir abad ke-19 tepatnya tahun 1893 di Lautan Teduh. Dua orang bersaudara, Syd dan Charles Cavil yang 
juga berkebangsaan Australia, mempopulerkan gaya bebas ini di Eropa pada tahun 1902. Selanjutnya, pada tahun 1903 mereka memperkenalkannya di Amerika Serikat (Dewayanti, 2008: 34). Geoffrey Corlett (1972) mendefinisikan gaya bebas gerakannya dapat ditinjau dari posisi tubuh (body position), gerakan tungkai (leg action), gerakan lengan(arm action), pernafasan (breathing), dan koordinasi tungkai-lengan-nafas (kick-breath coordination).

Gaya crawl oleh sebagian orang disebut gaya bebas. Sebetulnya istilah ini salah, sebab gaya bebas merupakan nama nomor perlombaan renang, sedangkan gaya crawl merupakan salah satu teknik renang. Pada setiap perlombaan nomor gaya bebas hampir semua perenang memilih gaya crawl maka gaya crawl sering dinamakan gaya bebas. Banyaknya perenang memilih gaya crawl saat mengikuti perlombaan dalam nomor gaya bebas karena gaya crawl merupakan gaya renang tercepat dibandingkan dengan ketiga gaya yang lain ialah gaya dada, gaya punggung dan gaya kupu-kupu (Maglischo, 1993: 15).

Prestasi olahraga ditentukan oleh beberapa faktor, diantaranya: (1) kekuatan atau strengh, (2) kecepatan atau speed, (3) daya tahan atau endurance, (4) daya otot atau muscular power, (5) daya lentur atau flexibility, (6) koordinasi atau coordination, (7) kelincahan atau agility, (8) keseimbangan atau balance, (9) ketepatan atau accuracy, dan (10) reaksi atau reaction (Sajoto, 1995: 8-10).

Ada kelompok unsur utama dari kondisi fisik yang dibutuhkan untuk dapat melakukan unjuk kerja yang baik, yaitu kekuatan, daya tahan dan kelentukan (Tyler, 1986: 13). Prestasi renang gaya bebas dipengaruhi oleh teknik, kecepatan, daya tahan, dan koordinasi. Teknik dalam gerakan yaitu dimana atlet dapat melakukan gerakan laju ke depan sesuai dengan mekanika dan peraturan yang dipakai pada suatu gaya dan melakukan koordinasi gaya tersebut dengan tepat. Waktu tempuh renang sangat penting karena merupakan tolak ukur keberhasilan bagi setiap perenang dalam mencapai finish. 
Peneliti melakukan survei di Club Bangka Swimming karena lemahnya atlet pada saat mengayuhkan tangan dan tungkai, disebabkan tidak kuatnya otot lengan karena latihan yang kurang teratur membuat gampang letih dan kurangnya pemanasan yang menyebabkan gerakan gaya bebas atlet tersebut. Oleh karena itu peneliti tertarik mengangkat permasalahan ini dengan judul Hubungan Kekuatan Otot Lengan dan Otot Tungkai terhadap Hasil Kecepatan Renang Gaya Bebas 50 Meter pada Atlet Putri Bangka Swimming Club.

\section{B. METODOLOGI PENELITIAN}

Penelitian ini bertujuan untuk menjelaskan hubungan antara kekuatan otot lengan dan otot tungkai baik secara sendiri-sendiri maupun bersama-sama terhadap hasil kecepatan renang gaya bebas 50 meter pada atlet putri Bangka Swimming Club. Penelitian ini tergolong pada jenis penelitian kuantitatif yang menggunakan teknik regresi dan korelasi baik tunggal maupun ganda. Adapun variabel yang dihubungkan dalam penelitian ini adalah kekuatan otot lengan $\left(\mathrm{X}_{1}\right)$ dan kekuatan otot tungkai $\left(\mathrm{X}_{2}\right)$, sedangkan variabel terikatnya yaitu hasil kecepatan renang gaya bebas 50 meter $(\mathrm{Y})$.

\section{Tempat dan Waktu Penelitian}

a. Waktu Penelitian

Penelitian ini dilaksanakan pada Club Bangka Swimming yang terletak di kota Bangka.

b. Tempat Penelitian

Penelitian ini bertempat di Kolam Loka Tirta Sungai Liat Bangka.

\section{Populasi}

Populasi dalam penelitian ini adalah seluruh atlet putri Club Bangka Swimming berjumlah 10 atlet. Pengambilan sampel pada penelitian ini dilakukan dengan teknik sampling jenuh yaitu teknik penentuan sampel bila semua anggota populasi digunakan sebagai sampel. Jumlah sampel penelitian 
ini adalah 10 orang. Sampel yang digunakan bersifat homogen karena hanya atlet putri saja sebagai objek yang diteliti.

\section{Teknik Pengumpulan Data}

Untuk mengukur kekuatan otot lengan dari testee digunakan alat pull and push dynamometer sedangkan kekuatan otot tungkai dengan menggunakan alat leg dynamometer dan hasil kecepatan renang gaya bebas dengan jarak 50 meter.

Instrumen atau alat pengumpul data dalam penelitian ini adalah sebagai prosedur pelaksanaan tes pengukuran. Tujuan dari adanya pelaksanaan tes adalah agar testee tidak salah dalam melakukan tes yang sesungguhnya, sehingga dalam pelaksanaan benar-benar dipahami. Berikut prosedur pelaksanaan tes kekuatan otot lengan dan kekuatan otot tungkai.

1) Kekuatan Otot Lengan

Dalam mengukur kekuatan otot lengan, alat yang digunakan adalah pull and push dynamometer test. Berikut prosedur dalam pengukuran otot lengan.

a) Testee berdiri tegak, posisi kaki terbuka kurang lebih $30 \mathrm{~cm}$.

b) Alat dipegang dengan kedua tangan di muka dada, posisi push and pull dynamometer menghadap ke depan dan kedua lengan atas dan bawah fleksi sejajar dengan bahu.

c) Lakukan gerakan menarik (pull) dan mendorong (push) pada alat dynamometer oleh kedua tangan sekuat-kuatnya dengan gerakan perlahan dan badan berdiri tegak. Gerakan dianggap gagal apabila dynamometer menyentuh dada, posisi lengan atas dan bawah tidak sejajar dengan bahu dan melakukan gerakan sentuhan.

d) Dari hasil tes yang dilakukan dua kali diambil yang terbaik, dinyatakan dalam satuan ukuran kilogram $(\mathrm{kg})$.

e) Petugas mencatat hasil dalam blangko pengukuran (Nurhasan, 2007: 162). 


\section{Gambar 1}

\section{Pull and Puss Dynamometer}

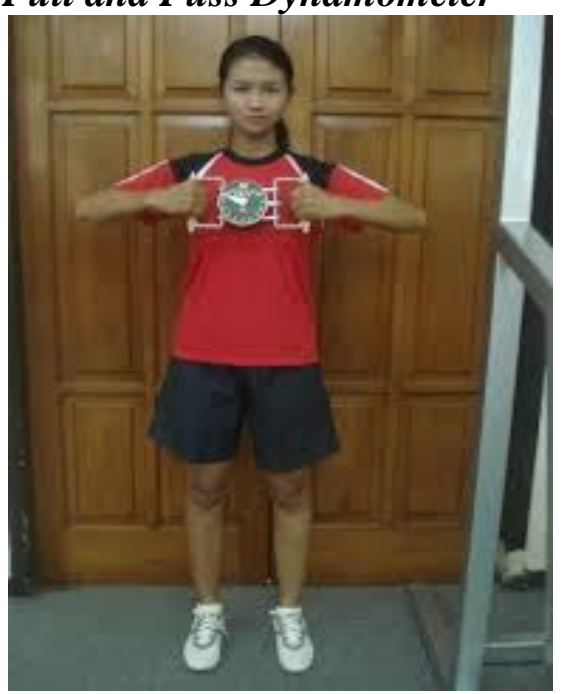

2) Kekuatan Otot Tungkai

Pengukuran kekuatan otot tungkai menggunakan metode leg dynamometer test. Berikut prosedur mengukur kekuatan otot tungkai.

a) Testee berdiri di atas tumpuan leg dynamometer tanpa alas kaki.

b) Kedua tangan memegang bagian tengah tongkat pegang dynamometer sedemikian rupa sehingga posisi punggung tetap tegak dan lutut membengkok membuat sudur $120^{\circ}$, pasang sabuk pembantu melingkari pinggang, ikatan jangan terlalu kuat karena hanya sebagai penahan ujung tali yang dikaitkan pada tongkat pegangan leg dynamometer.

c) Lakukan gerakan meluruskan kedua tungkai atas dan bawah sekuatnya dengan sekali tarikan.

d) Posisi badan tegak menghadap ke depan dan kedua tangan memegang tongkat pegangan dynamometer.

e) Tes dilakukan dua kali dan diambil yang terbaik. Petugas mencatat hasil dalam blangko pengukuran. Pembacaan skala dinyatakan 
dalam satuan kilogram sampai ketelitian 0,5 satuan kilogram (Nurhasan, 2007: 161).

Gambar 2

Leg Dynamometer

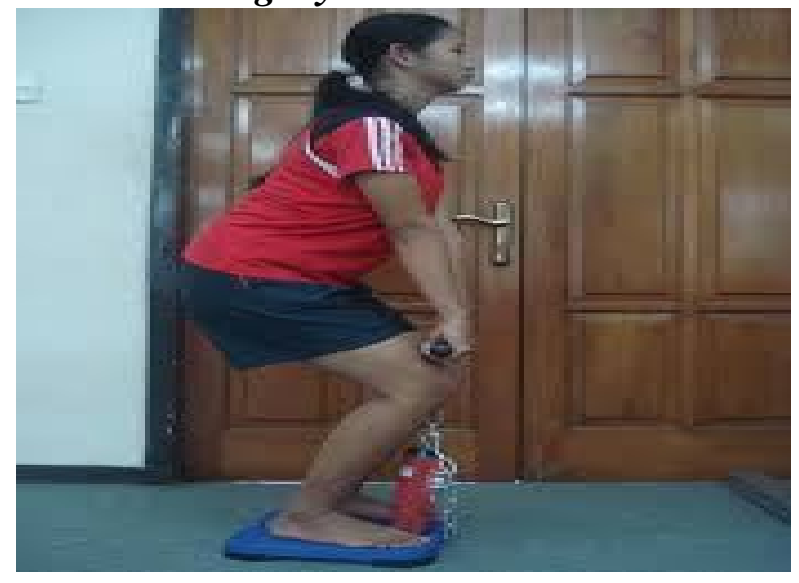

3) Kecepatan Renang 50 Meter Gaya Bebas

Pengukuran kecepatan renang 50 meter gaya bebas menggunakan alat antara lain kolam renang, stop wacth, blangko pengukuran, dan alat tulis.

Berikut langkah-langkah tes kecepatan renang 50 meter.

a. Pertama testee berdiri di atas balok start.

b. Setelah ada aba-aba testee melakukan start dari balok start dilanjutkan melakukan renang gaya bebas menempuh jarak 50 meter.

c. Waktu yang dicatat adalah waktu yang dibutuhkan perenang mulai dari start sampai finish dengan menggunakan stop watch.

d. Hasil testee yang diambil adalah waktu yang ditempuh sejauh 50 meter oleh sampel dan dicatat oleh peneliti, kesempatan diberikan satu kali kesempatan. 


\section{Teknik Analisa Data}

Teknik analisa data yang digunakan adalah teknik analisis regresi, korelasi sederhana dan ganda. Hipotesis 1 dan 2 dianalisis dengan regresi dan korelasi sederhana, sedangkan hipotesis 3 dianalisis dengan korelasi ganda. Sebelum melakukan analisis terhadap data di atas, dilakukan uji persyaratan sebagai berikut.

1. Uji normalitas untuk mengetahui apakah data berasal dari populasi yang berdistribusi normal, dilakukan dengan uji Lilliefors.

2. Uji linearitas regresi $X_{1}$ atas $Y$ dan $X_{2}$ atas $Y$ menggunakan teknik regresi sederhana.

3. Uji independen variabel bebas, digunakan untuk memeriksa apakah variabel berat badan dan tinggi badan benar-benar bebas atau satu sama lainnya tidak berkorelasi secara signifikan, sehingga prediktor benar-benar murni nilai prediksinya.

4. Analisis regresi dan korelasi ganda, analisis ini digunakan untuk mengetahui hubungan variabel kekuatan otot lengan $\left(\mathrm{X}_{1}\right)$ dan kekuatan otot tungkai $\left(\mathrm{X}_{2}\right)$ secara bersama-sama terhadap hasil kecepatan renang gaya bebas dengan jarak 50 meter, keberartian korelasi dan persamaan regresinya menggunakan uji F (Sugiyono, 2012: 256).

\section{HASIL PENELITIAN DAN PEMBAHASAN}

1. Kekuatan Otot Lengan

Hasil data dari tes kekuatan otot lengan dapat dikumpulkan dengan menggunakan tes pull and push dynamometer. Masing-masing atlet melakukan dua kali tes yang diambil nilai terbaik diperoleh hasil jumlah nilai tertinggi, nilai rendah, dan rata-rata. Berikut ini mengenai tabel data-data lengkapnya. 
Tabel 1. Deskripsi Data Kekuatan Otot Lengan

\begin{tabular}{clc}
\hline No & Nama & $\begin{array}{c}\text { Pull and Push } \\
\text { Dynamometer }\end{array}$ \\
\hline 1. & Prisilia & $19 \mathrm{~kg}$ \\
2. & Embun & $42 \mathrm{~kg}$ \\
3. & Tasya & $18 \mathrm{~kg}$ \\
4. & Anggun & $15 \mathrm{~kg}$ \\
5. & Sari & $26 \mathrm{~kg}$ \\
6. & Patricia & $34 \mathrm{~kg}$ \\
7. & Yusnita Sari & $27 \mathrm{~kg}$ \\
8. & Novi Wulandari & $25 \mathrm{~kg}$ \\
9. & Egedia & $27 \mathrm{~kg}$ \\
10 & SafitriI & $20 \mathrm{~kg}$ \\
\hline
\end{tabular}

\begin{tabular}{cc}
\hline Variabel & Kekuatan Otot Lengan $(\mathrm{Kg})$ \\
\hline Nilai tertinggi & 42 \\
Nilai terendah & 15 \\
Rata-rata & 26,3 \\
\hline Sumber: Data penelitian 2017
\end{tabular}

Deskripsi data hasil pengukuran berdasarkan angka kasar atau data mentah hasil pengukuran variabel kekuatan otot lengan yang memiliki ratarata sebesar 26,3 dengan nilai tertinggi $42 \mathrm{~kg}$ dan nilai terendah $15 \mathrm{~kg}$. Di bawah ini disajikan mengenai distribusi frekuensi data hasil kekuatan otot lengan menggunakan tes pull and push dynamometer. Dianalisis menggunakan aturan struges sebagai berikut.

1) Rentang = data terbesar - data terkecil

$$
\begin{aligned}
& =42-15 \\
& =27
\end{aligned}
$$

2) Kelas interval $=1+3,3 \log (n)$

$$
\begin{aligned}
& =1+3,3 \log 10 \\
& =1+3,3(1) \\
& =4,3 \approx 4
\end{aligned}
$$




$$
\text { 3) } \begin{aligned}
\text { Panjang kelas }= & \frac{\operatorname{Re} n \tan g}{K} \\
& =\frac{27}{4} \\
& =6,7 \approx 7
\end{aligned}
$$

Tabel 2. Distribusi Frekuensi Hasil Tes Kekuatan Otot Lengan

\begin{tabular}{ccc}
\hline Interval Kelas & Distribusi frekuensi & Persentase \\
\hline $13-20$ & 4 & 40 \\
$21-28$ & 3 & 30 \\
$29-36$ & 1 & 10 \\
$37-44$ & 2 & 20 \\
$\sum$ & 10 & 100 \\
\hline
\end{tabular}

Berdasarkan tabel di atas ternyata dari 10 responden hanya 4 orang (40\%) berada di interval kelas 13 - 20, 3 orang (30\%) berada di interval klas $21-28$, 1 orang $(10 \%)$ berada di interval $29-36$, dan 2 orang $(20 \%)$ berada di interval klas 37 - 44. Untuk lebih jelasnya dapat dilihat distribusi data tersebut dalam grafik berikut.

\section{Gambar 3. Diagram Histogram Kekuatan Otot Lengan}
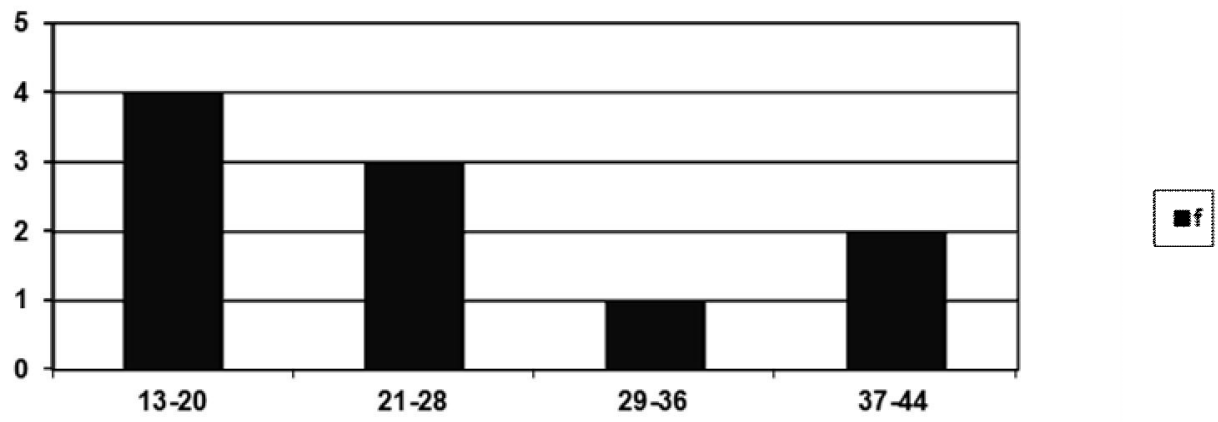

2. Kekuatan Otot Tungkai

Hasil data dari tes kekuatan otot tungkai dapat dikumpulkan dengan menggunakan tes leg dynamometer. Berikut ini mengenai tabel data-data lengkapnya. 
Tabel 3. Deskripsi Data Penilaian Kekuatan Otot Tungkai

\begin{tabular}{clc}
\hline No & Nama & $\begin{array}{c}\text { Leg } \\
\text { Dynamometer }\end{array}$ \\
\hline 1. & Prisilia & $49,0 \mathrm{~kg}$ \\
2. & Embun & $61,5 \mathrm{~kg}$ \\
3. & Tasya & $54,0 \mathrm{~kg}$ \\
4. & Anggun & $44,5 \mathrm{~kg}$ \\
5. & Sari & $46,0 \mathrm{~kg}$ \\
6. & Patricia & $45,0 \mathrm{~kg}$ \\
7. & Yusnita Sari & $44,3 \mathrm{~kg}$ \\
8. & Novi Wulandari & $45,1 \mathrm{~kg}$ \\
9. & Egedia & $43,6 \mathrm{~kg}$ \\
10 & SafitriI & $42,9 \mathrm{~kg}$ \\
\hline
\end{tabular}

\begin{tabular}{cc}
\hline Variabel & Kekuatan Otot Tungkai \\
\hline Nilai tertinggi & 61,5 \\
Nilai terendah & 42,9 \\
Rata-rata & 47,59 \\
\hline
\end{tabular}

Sumber: Data penelitian 2017

Dari hasil penelitian dapat diketahui bahwa hasil tes kekuatan otot tungkai yang tertinggi adalah 61,5 sedangkan terendah adalah 42,9. Di bawah ini disajikan mengenai distribusi frekuensi data hasil kekuatan otot tungkai. Dianalisis menggunakan aturan struges sebagai berikut.

1) Rentang = data terbesar - data terkecil

$$
\begin{aligned}
& =61,5-42,9 \\
& =18,6
\end{aligned}
$$

2) Kelas interval $\quad=1+3,3 \log (n)$

$$
\begin{aligned}
& =1+3,3 \log 10 \\
& =1+3,3(1)
\end{aligned}
$$$$
=4,3 \approx 4
$$

3) Panjang kelas $=\frac{\operatorname{Re} n \tan g}{K}$

$$
\begin{aligned}
& =\frac{18,6}{4} \\
& =4,6
\end{aligned}
$$


Tabel 4. Distribusi Frekuensi Hasil Kekuatan Otot Tungkai

\begin{tabular}{ccc}
\hline Interval Kelas & Distribusi Frekuensi & Persentase \\
\hline $42,9-47,5$ & 7 & 70 \\
$47,6-52,2$ & 1 & 10 \\
$52,3-56,9$ & 1 & 10 \\
$57,0-61,6$ & 1 & 10 \\
$\sum$ & 10 & 100 \\
\hline
\end{tabular}

Berdasarkan tabel di atas ternyata dari 10 responden 7 orang $(70 \%)$ berada di interval kelas 42,9 - 47,5, 1 orang (10\%) berada di interval klas 47,6 - 52,2, 1 orang $(10 \%)$ berada di interval 52,3 - 56,9, dan 1 orang (10\%) berada di interval klas 57,0 - 61,6. Untuk lebih jelasnya dapat dilihat distribusi data tersebut dalam grafik berikut:

\section{Gambar 4. Diagram Histogram Kekuatan Otot Tungkai}
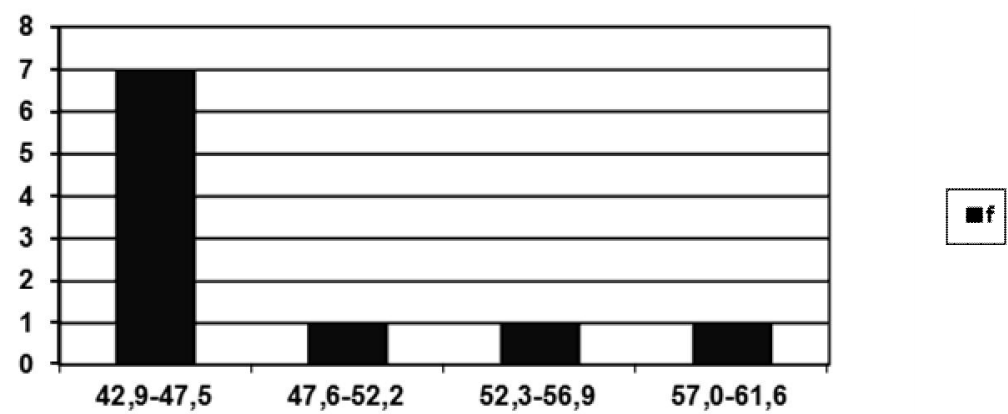

3. Kecepatan Renang Gaya Bebas

Hasil data dari tes kecepatan renang gaya bebas dapat dilakukan dengan menempuh dengan jarak 50 meter dengan alat bantu untuk mengukur kecepatan menggunakan stop wacth. Masing-masing atlet melakukan 2x tes yang diambil nilai terbaik diperoleh hasil jumlah nilai tertinggi, nilai rendah dan rata-rata. Berikut ini mengenai tabel data-data lengkapnya: 
Tabel 5. Deskripsi Data Kecepatan Renang

\begin{tabular}{llc}
\hline No & Nama & $\begin{array}{c}\text { Kecepatan Renang } \\
50 \text { meter (detik) }\end{array}$ \\
\hline 1. & Prisilia & 39,86 detik \\
2. & Embun & 40,03 detik \\
3. & Tasya & 48,42 detik \\
4. & Anggun & 38,50 detik \\
5. & Sari & 41,17 detik \\
6. & Patricia & 47,30 detik \\
7. & Yusnita Sari & 39,98 detik \\
8. & Novi Wulandari & 42,59 detik \\
9. & Egedia & 45,56 detik \\
10 & SafitriI & 46,75 detik \\
\hline
\end{tabular}

\begin{tabular}{cc}
\hline Variabel & Kecepatan Renang (detik) \\
\hline Nilai tertinggi & 38,50 \\
Nilai terendah & 48,42 \\
Rata-rata & 43,01 \\
\hline
\end{tabular}

Sumber: Data penelitian 2017

Dari hasil penelitian dapat diketahui bahwa hasil tes kecepatan renang yang tertinggi adalah 38,50 sedangkan terendah adalah 48,42. Dibawah ini disajikan mengenai distribusi frekuensi data hasil tes kecepatan renang. Dianalisis menggunakan aturan struges sebagai berikut.

1) Rentang = data terbesar - data terkecil

$$
\begin{aligned}
& =48,42-38,50 \\
& =9,92
\end{aligned}
$$

2) Kelas interval $\quad=1+3,3 \log (\mathrm{n})$

$$
\begin{aligned}
& =1+3,3 \log 10 \\
& =1+3,3(1)
\end{aligned}
$$$$
=4,3 \approx 4
$$

3) Panjang kelas $\quad=\frac{\operatorname{Re} n \tan g}{K}$

$$
\begin{aligned}
& =\frac{9,92}{4} \\
& =2,4
\end{aligned}
$$


Tabel 6. Distribusi Frekuensi Hasil Tes Kecepatan

\begin{tabular}{rcc}
\hline Interval Kelas & Distribusi frekuensi & Persentase \\
\hline $38,5-40,9$ & 4 & 40 \\
$41,0-43,4$ & 2 & 20 \\
$43,5-45,9$ & 1 & 10 \\
$46,0-48,4$ & 3 & 30 \\
\hline$\sum$ & 10 & 100 \\
\hline
\end{tabular}

Berdasarkan tabel di atas ternyata dari 10 teste hanya 4 orang (40\%) berada di interval kelas 38,5 - 40,9, 2 orang (20\%) berada di interval klas 41,0 - 43,4, 1 orang (10\%) berada di interval 43,5 - 45,9, dan 3 orang (30\%) berada di interval 46,0 - 48,4. Untuk lebih jelasnya dapat dilihat distribusi data tersebut dalam grafik berikut:

\section{Gambar 5. Diagram Histogram Kecepatan Renang}

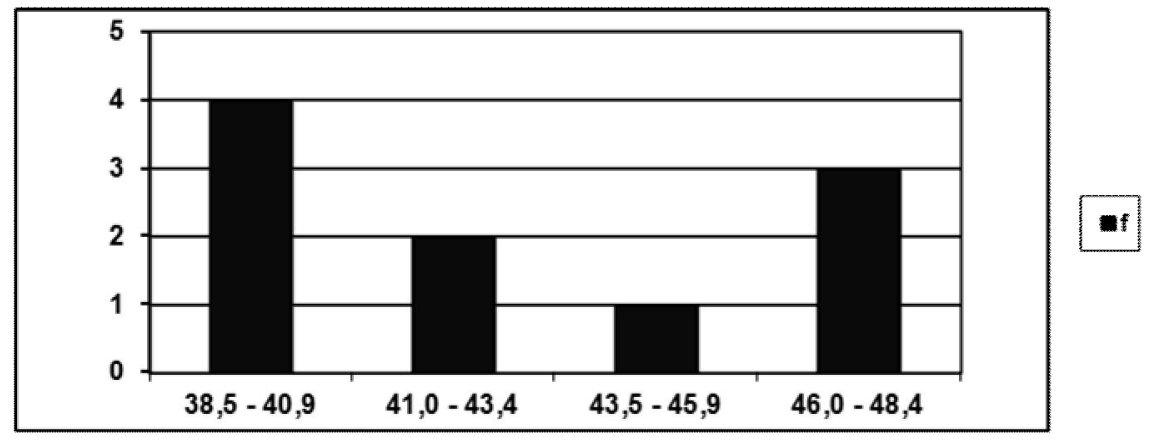

\section{SIMPULAN DAN SARAN}

Berdasarkan analisis data dan pembahasan hasil penelitian maka dapat ditarik kesimpulan sebagai berikut.

1. Ada hubungan yang signifikan sebesar $0,75 \%$ antara kekuatan otot lengan dengan hasil kecepatan renang 50 meter gaya bebas pada atlet putri Club Bangka Swimming. 
2. Ada hubungan yang signifikan sebesar $0.63 \%$ antara kekuatan otot tungkai dengan hasil kecepatan renang 50 meter gaya bebas pada atlet putri Club Bangka Swimming.

3. Ada hubungan yang signifikan sebesar $0,83 \%$ antara kekuatan otot lengan dan kekuatan otot tungkai dengan hasil kecepatan renang 50 meter gaya bebas pada atlet putri Club Bangka Swimming.

Berdasarkan hasil penelitian dan kesimpulan dari penelitian ini, maka peneliti mengajukan saran-saran sebagai berikut.

1. Bagi para pelatih dalam memberikan latihan renang gaya bebas kepada para atlet hendaknya diimbangi dengan peningkatan kondisi fisik berupa kekuatan tarik maupun kekuatan dorong otot lengan serta kekuatan otot tungkai sehingga pelatihan yang dilakukan dapat berhasil guna dan berdaya guna.

2. Bagi atlet dapat mengetahui bentuk tes kekuatan otot lengan dan otot tungkai perenang guna menunjang kecepatan perenang dalam berenang sesuai gaya yang sedang diajarkan atau dilatih.

3. Bagi peneliti lain yang hendak mengadakan penelitian sejenis, hendaknya menjadikan hasil penelitian ini sebagai bahan referensi agar diperoleh hasil yang lebih optimal.

\section{DAFTAR PUSTAKA}

Saleh, Agung Purwandono. 2008. Olahraga Renang. Yogyakarta: Wimaya Press.

Bill, Sweetenham \& John Atkinson., 2003. Championship Swim Training. USA: Human Kinetics.

C.T, Dewayanti. 2008. Belajar Renang.Semarang: Aneka Ilmu.

Corlett, Geoffrey., 1972.Swimming Teaching (Theory and Practice). London: Kaye \& Ward.

Maglischo, Ernest W. 1993. Swiming Even Faster. London: Arizona State University. 
Nurhasan. 2007. Tes dan Pengukuran Olahraga. Bandung: FPOK UPI.

Rob, Oor C. dan Jane B. Tyler. 1986. Dasar-Dasar Renang. Bandung: Angkasa.

Sajoto, M. 1995. Peningkatan dan Pembinaan Kekuatan Kondisi Fisik dalam Olahraga. Semarang: Dahara Prize.

Sugiyono. 2012. Metode Penelitian Pendidikan Pendekatan Kuantitatif, Kualitatif, dan $R \& D$. Bandung: Alfabeta

Thomas, David G. 2000. Renang Tingkat Mahir, terjemahan Alfons Palangkaraya. Jakarta: Raja Grafindo Persada. 